\title{
A Reliable Method of Pile Load Test on Cast-in-Situ Pile Group of Existing Building for Retrofitting
}

\author{
Upal Mohammad Towfiqul Quadir \\ Department of Civil Engineering, Military Institute of Science and Technology, Dhaka 1206, Bangladesh
}

\begin{abstract}
Following the foundation failure of a building, with an aim of economical solution to strengthen other existing buildings of the same project, a new arrangement was implemented experimentally to test the adequacy of load bearing capacity of a few selected cast-in-situ RCC (reinforced cement concrete) pile groups without demolishing the existing buildings. In this test, the column bottom of an existing building was removed by the help of scaffolding and after that a frame system consisting tension piles and hollow beam was constructed over the pile cap of the to be tested pile group. The load was tested by the help of hydraulic jack system and the constructed frame system. This paper contains the detailed plan, arrangement and method of the test with illustrations. The deflection and loading data analysis is also included which was performed to determine the outcome of the test. Through this test method the appropriate assessment of capacity of pile group of existing building could be done successfully and in result the structure could be saved by only super structure retrofitting.
\end{abstract}

Key words: Cast-in-situ, pile, load test, load bearing capacity, retrofitting.

\section{Introduction}

Pile load tests are performed to find out if the pile have a certain least capacity or not [1]. In modern days, pile load tests are being performed by various methods such as conventional method, quick load test method or a modern static load test method such as self-balanced load test method [2, 3]. Even artificial neural networks are being used to predict the pile bearing capacity [4]. In modern era, some researches have also been performed on the degree of reliability on the conceptual frameworks to find out the pile capacity [5]. Usually, pile load tests are performed to find out the ultimate load bearing capacity and skin friction considering the residual stresses inside the pile [6]. Normally the pile load tests are performed on the piles before constructing the super structure. That is why all the methods available for pile load tests are usually for piles without a structure over them. One of the methods to test the load bearing capacity of the piles of an

Corresponding author: Upal Mohammad Towfiqul Quadir, M.Sc., research field: structural engineering. E-mail: towfiq@ce.mist.ac.bd. existing structure was planned and applied in a retrofitting project in Dhaka which is discussed in this paper.

The structure of a building of Dhalpur Cleaners Colonies project of DCC (Dhaka City Corporation) collapsed. The building was five storied residential building and was less than ten years old. The soil condition in that area was medium stiff which is why the buildings where constructed with pile foundation. DCC decided to strengthen the remaining existing buildings of the same project. But as the primary cause of the structural failure was found to be the load baring capability failure of the foundation, some experts advised reconstruction of the structures from foundation level. But as it would be a matter of huge budget for same project, DCC desperately looked for an alternative economical solution. Then a structural consultant company named Shaheedullah and New Associates Ltd. who were experienced in these types of structural solutions for over twenty years, came forward offering an experimental but promising solution. In their solution, they planned to test the load 
bearing capacity of a critical pile group of the existing building structure by the help of hydraulic jack constructing a set of tension pile and hollow beam system around the to-be-tested cast in situ pile group. As there is an existing structure over the pile cap, they suggested the removal of column bottom by the help of scaffolding. And for the placement of boring equipment for the construction of friction pile which falls inside the floor area, they suggested removal of the portion of slabs which are directly over the to-be-constructed friction piles location.

\section{Description}

\subsection{Preparation}

At first, a most critical pile group at a most convenient location where the friction piles could be constructed and which carried greater load than other pile groups was selected for testing. The plan view of the pile cap of the selected pile group is shown in Fig. 1. Four friction piles of $45 \mathrm{~cm}$ diameter were planned to be constructed around the selected pile group of which one friction pile fell inside the floor area. So as the first step of the process, an area of around $10 \mathrm{~m}^{2}$ of all the five slabs were removed at the place where the friction pile was planned to be constructed. Four $45 \mathrm{~cm}$ diameter friction piles of $18 \mathrm{~m}, 19.5 \mathrm{~m}$ and $21 \mathrm{~m}$ length were constructed around the pile group. Different lengths were chosen due to different friction capacity of soil in the respective locations. After that, the ground floor segment of the column was replaced by some angular support as scaffolding. The column bottom was demolished after that. A cross shaped steel box frame was placed over the pile cap for proper distribution of load while testing. After that a hollow steel beam system containing three hollow beams was constructed over the pile cap connecting the friction piles as support. The steel made hollow beams were welded to the extended reinforcements of the friction pile. At first $0.75 \mathrm{~cm}$ thickness was chosen for the hollow steel beams as per local availability of the steel plates and the highest load to be applied. A hydraulic pump jack was placed between the hollow steel beam arrangement and the cross shaped steel box frame on the pile cap. To resist failure due to shear force, some angular bars were welded to the steel beams at the portion where the hydraulic jack was placed. A precision strain dial gauge with magnetic base was used to determine the deflection. The jack pump system had a capacity of applying $300 \mathrm{t}$ and the strain dial gauge to monitor pile settlement had maximum run of $50 \mathrm{~mm}$ with a sensitivity of $0.01 \mathrm{~mm}$. The information of the to-be-tested pile group is shown in Table 1.

As per the designated engineer of DCC, the design load for the group pile was $86 \mathrm{t}$ which was derived from the calculated column load of the design data of that building which data was used at the time of that building's construction. ASTM(1989) specifies a test load of 1.5 times the design load for individual service piles. So it was decided that a test load of $129 \mathrm{t}$ should be applied to the service group pile.

\subsection{Testing (First Phase)}

It was planned to apply the test load of $129 \mathrm{t}$ in six approximately equal increments. The elevation and parts of the whole arrangement is shown in Figs. 2 and 3. While applying the load, in one of the initial loading stages, it was found that one of the beam of the steel hollow beam system failed due to the failure of one of the friction piles. The test was stopped for this reason and corrective measures were started to be planned.

\subsection{Testing (Second Phase)}

As one of the friction pile failed in the first phase and also the hollow beam, a new set of friction piles were constructed and a new arrangement of steel hollow beam was introduced. The elevation and all the details of the new arrangement are shown in Figs. 4-11. The

Table 1 Physical and technical descriptions of the service group pile [7].

\begin{tabular}{lllll}
\hline $\begin{array}{l}\text { Service group } \\
\text { pile No. }\end{array}$ & $\begin{array}{l}\text { No. of piles } \\
\text { in the group }\end{array}$ & $\begin{array}{l}\text { Pile diameter } \\
(\mathrm{mm})\end{array}$ & $\begin{array}{l}\text { Pile } \\
\text { (m) }\end{array}$ & length \\
\hline 1 & 5 & 450 & 12.5 & \\
\hline
\end{tabular}




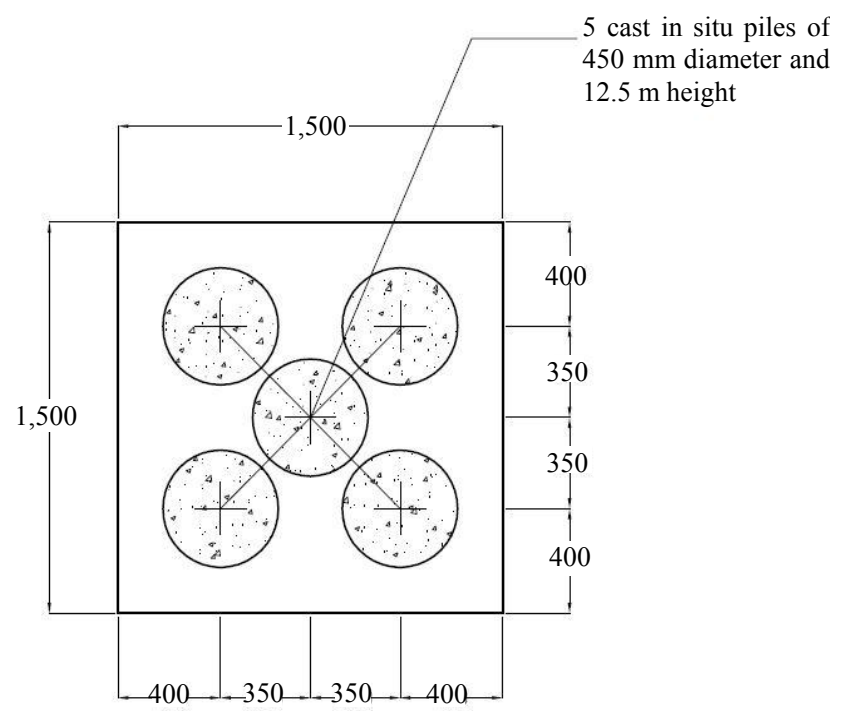

Fig. 1 Plan view of pile cap of the to-be-tested pile group.

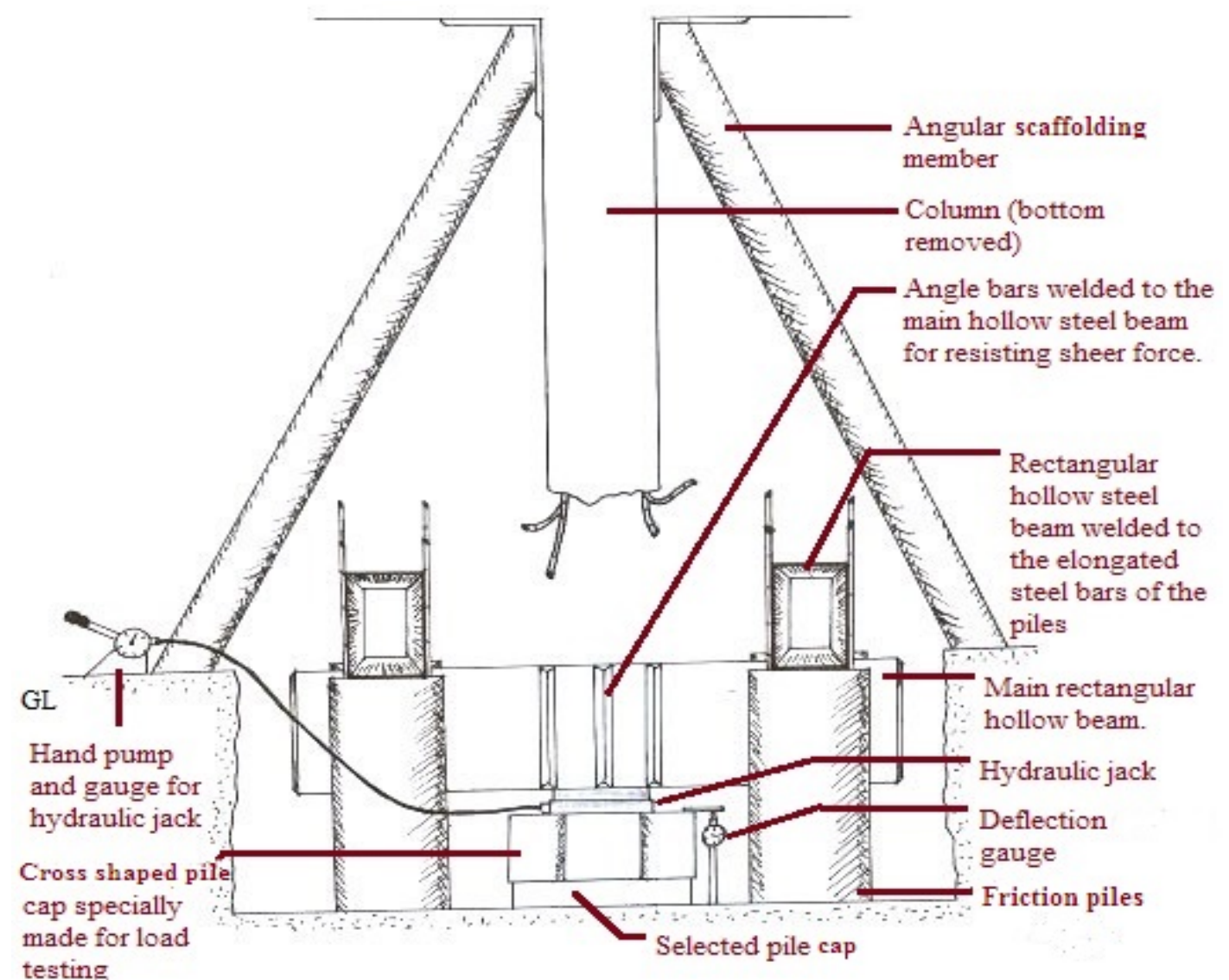

Fig. 2 Elevation of first arrangement.

thickness of the steel plates of the hollow beams were increased to $1.5 \mathrm{~cm}$ to be on the safe side. Like the first phase, it was again planned to apply a test load of $129 \mathrm{t}$ (1.5 time the design loads) in six approximately equal increment. The hydraulic jack was placed between the steel hollow beam system and the cross shaped steel box placed over the pile cap. The plan of both arrangements are shown in Fig. 12. Then the load was 
started to be applied by the help of hand pump connected to the hydraulic jack. The current loading stage after each increment of load was maintained until the rate of settlement was not greater than $0.25 \mathrm{~mm} / \mathrm{h}$ or $2 \mathrm{~h}$ had elapsed whichever occurred first. After that the next load increment was applied. This procedure has been followed for all increments of load. When the load was raised to $132.46 \mathrm{t}$, it was found that the pile group was able to sustain this load. At that point, to be more assured about the load baring capacity of the pile group, it was decided to raise the load to a magnitude of $150.5 \mathrm{t}$ (1.75 times the design load). As per the decision the load was raised to $152.29 \mathrm{t}$, consequently.

It was observed that the pile group was able to sustain the load of $152.29 \mathrm{t}$. The total settlement at the test load of $152.29 \mathrm{t}$ was found to be $13.85 \mathrm{~mm}$.

After that, the test load was then released with four step decrement. The elastic rebound of the pile due to unloading was measured by keeping the strain dial gauges attached to a pile. By this the final net settlement of the service group pile was found to be $10.67 \mathrm{~mm}$.

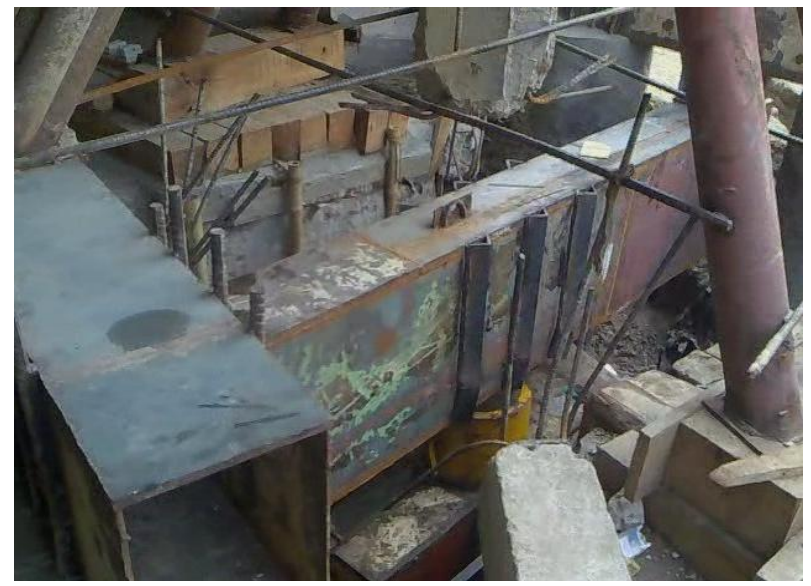

Fig. 3 Parts of first arrangement.

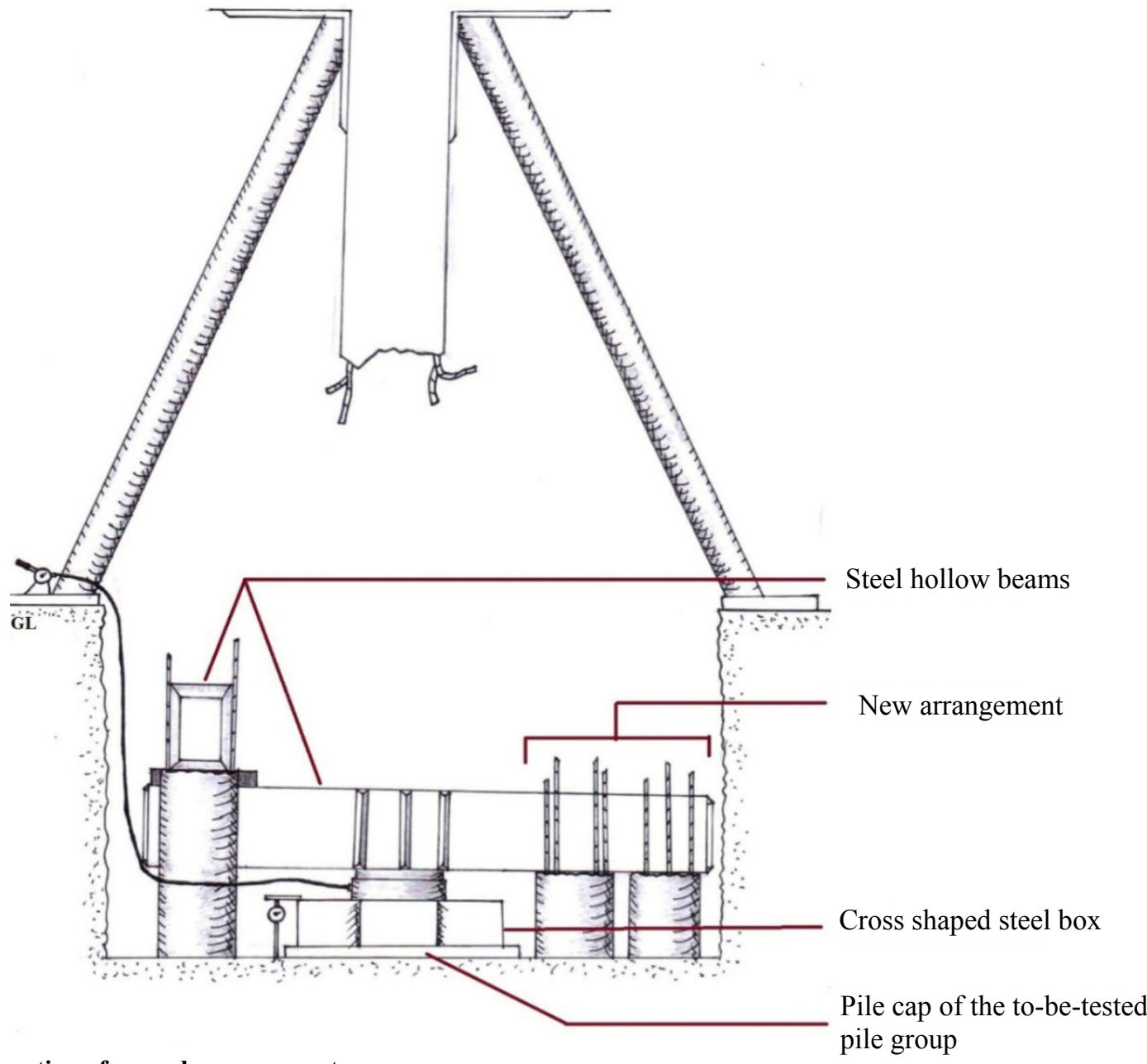

Fig. 4 Elevation of second arrangement. pile group 


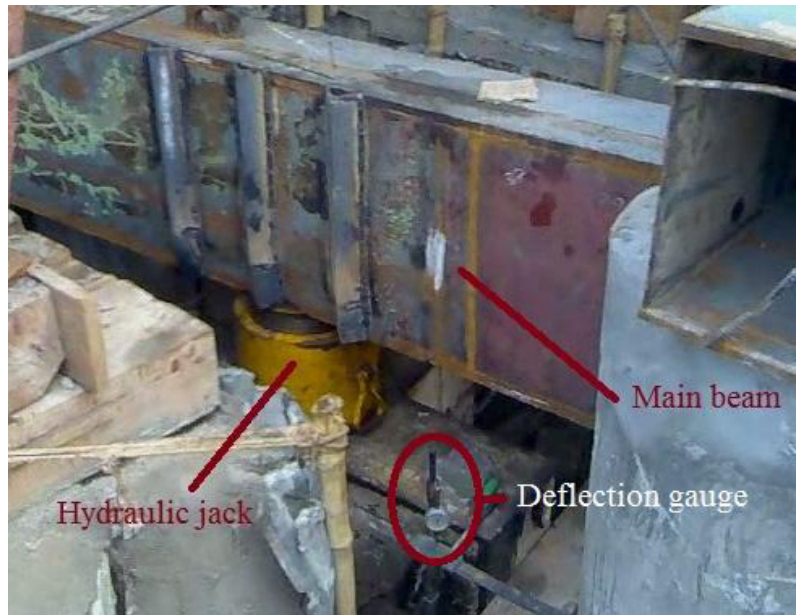

Fig. 5 Parts of second arrangement (1).

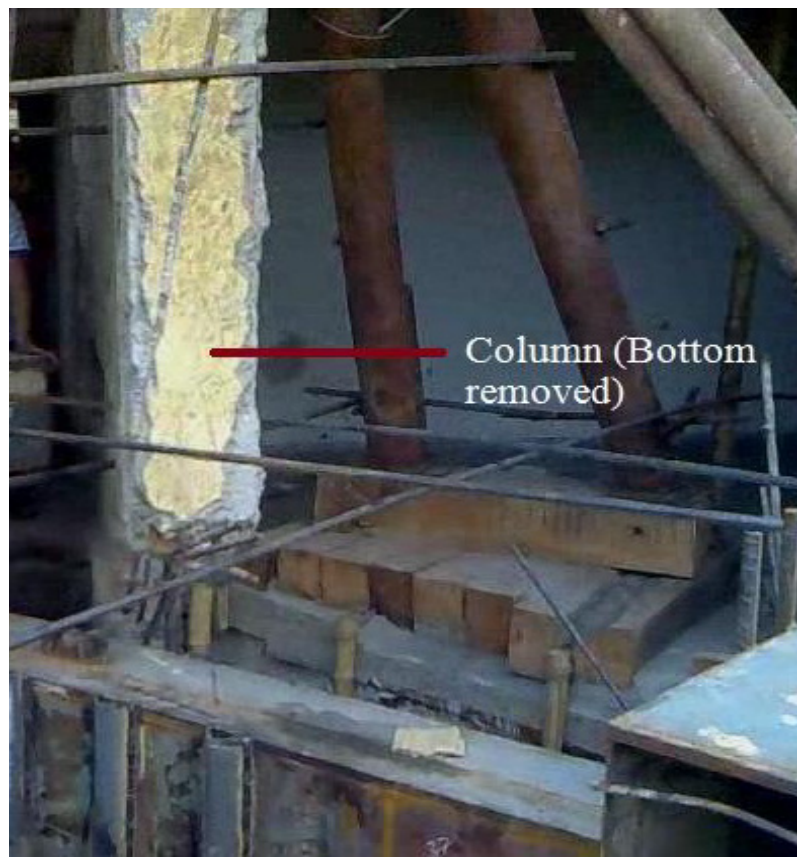

Fig. 6 Parts of second arrangement (2).

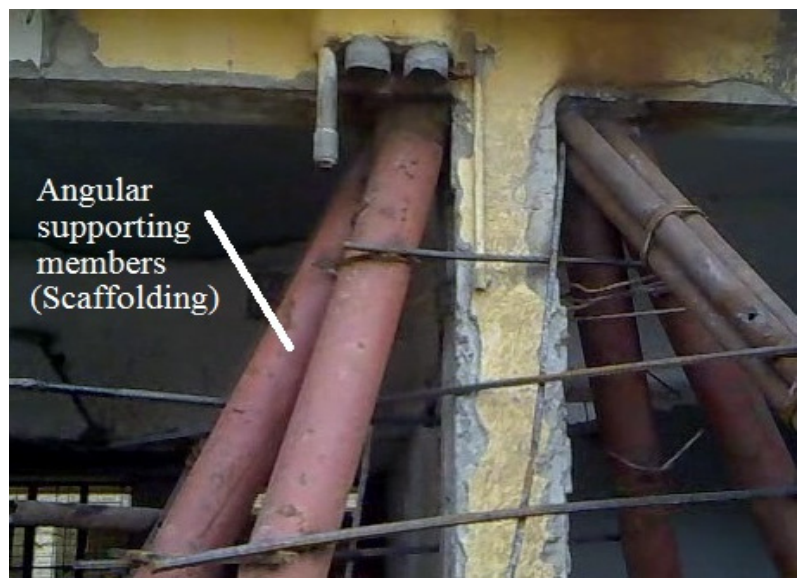

Fig. 7 Parts of second arrangement (3).

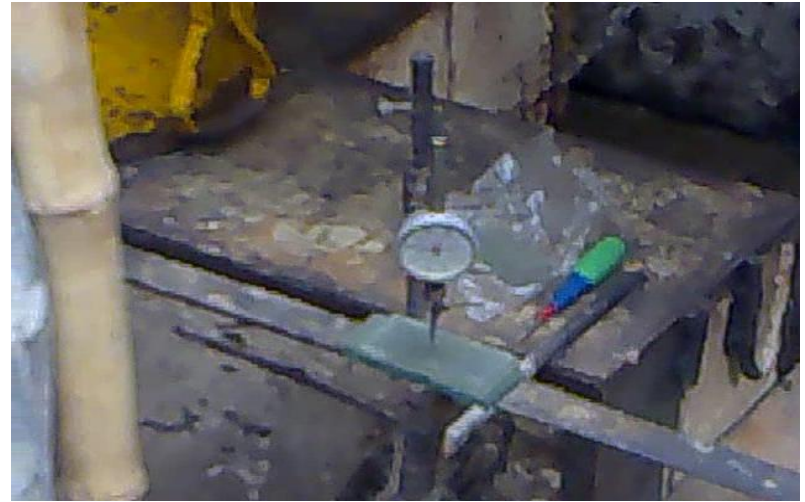

Fig. 8 Strain dial gauge.

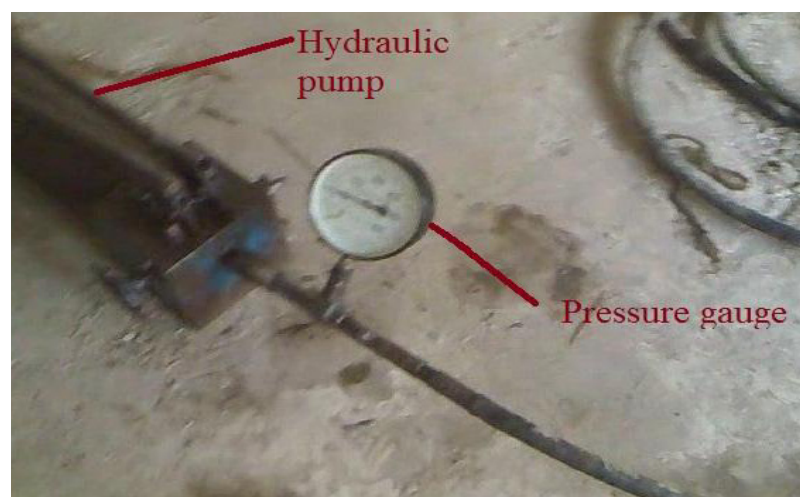

Fig. 9 Hand pump and gauge of hydraulic jack.

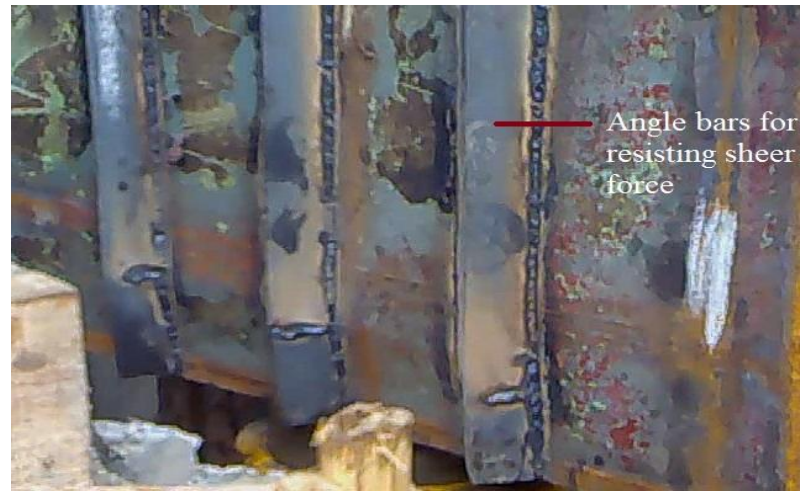

Fig. 10 Parts of second arrangement (4).

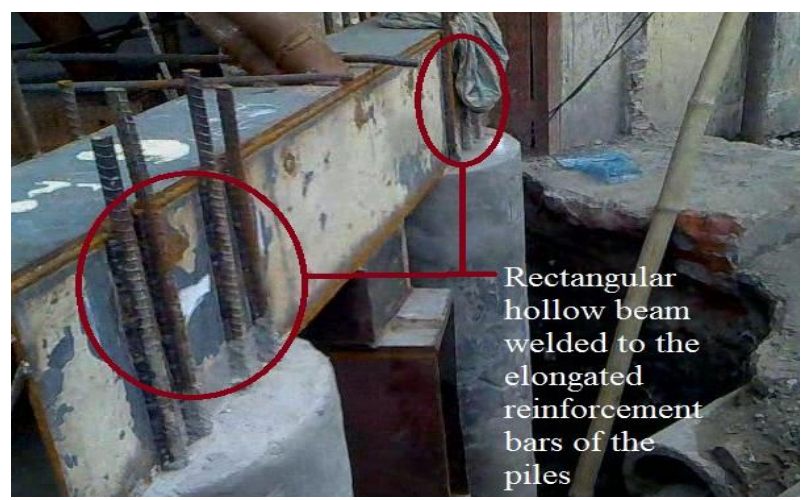

Fig. 11 Parts of second arrangement (5). 

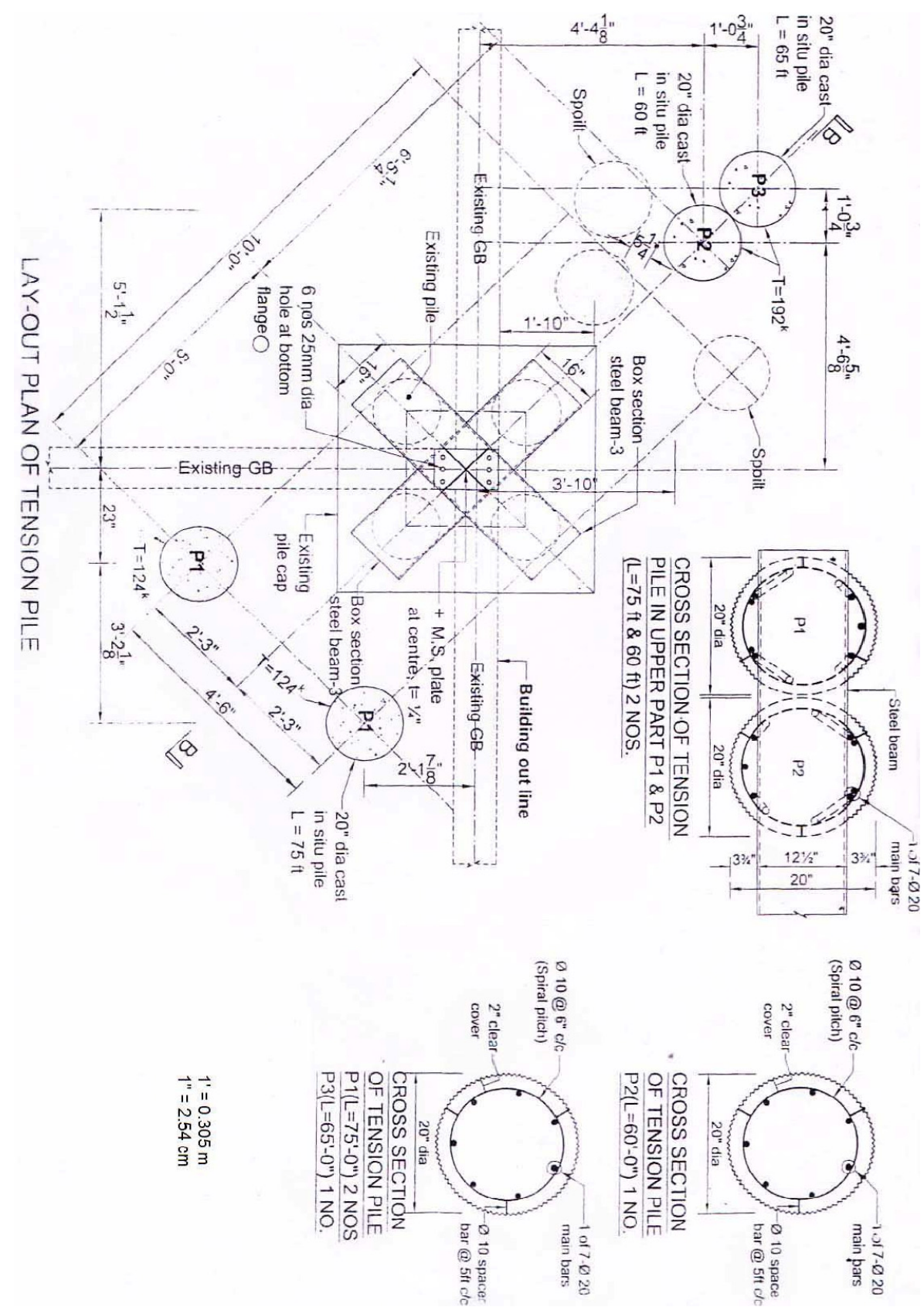

Fig. 12 Plan of both arrangements. Friction piles of first arrangement is indicated by "Spoilt" [8].

\section{Results and Discussion}

The load settlement time curve and load settlement curve for the test are shown in Figs. 13 and 14, respectively.

According to the test, the maximum settlement was found to be $13.85 \mathrm{~mm}$ which is lower than the maximum allowable settlement of $25 \mathrm{~mm}$ according to ACI code. So from this test, it was clear that the building foundation was capable to sustain the design load unlike the foundation of the building that already collapsed. Through this experimental method, many buildings of the same project of which the foundation was capable were saved from demolition of the whole structure, which economically contributed a lot by saving a huge budget of the government of a developing country as Bangladesh. 
Building-A; Service Group Pile No 1; Number of Piles in the Group $=5$ Pile Type: Cast-in-Situ; Pile length : $12.5 \mathrm{~m}$ : Pile Dia. : $450 \mathrm{~mm}$

Test Type: Miantained Loading Static Axial Compression Maximum Test Load: 152.29 tonne ( 1 tonne $=1,000 \mathrm{~kg})$

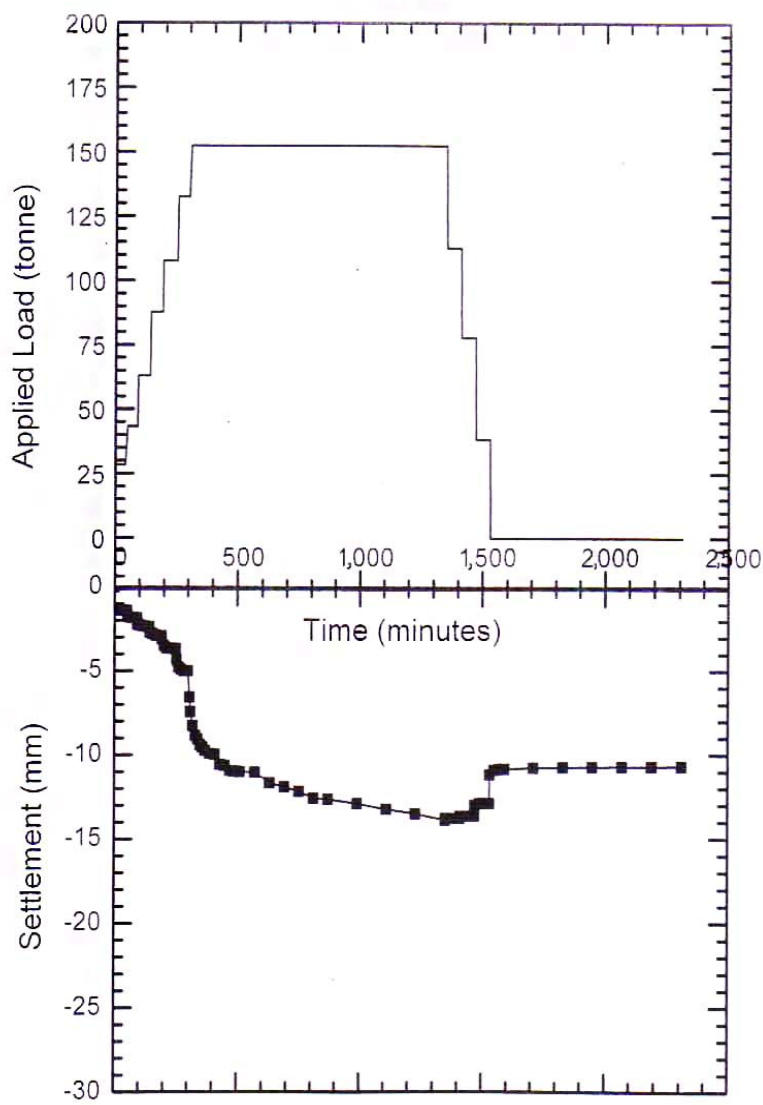

Fig. 13 Load-time-settlement curves of the tested pile group [7].

\section{Conclusions}

The main purpose of this experiment was to determine the load bearing capacity of a service pile group of an existing building which was successfully done. Later on, after this test, the building super structures of DCC were strengthened as per necessity as the problem was found not to be in the sub structure/foundation. This experimental method opened various scopes of future research as well, such as reconstruction of reinforced concrete columns after removal due to retrofitting works, easier method to test the load bearing capacity of an existing building, using constructed friction piles as part of the foundation of an existing structure.
Building-A. Senvice Group Pile No: 1. Number of Piles in the Group $=5$ Pile Type: Cast-in-Situ; Pile length : $12.5 \mathrm{~m}$; Pile Dia. : $450 \mathrm{~mm}$

Test Type: Miantained Loading Static Axial Compression Maximum Test Load: 152.29 tonne ( 1 tonne $=1,000 \mathrm{~kg}$ )

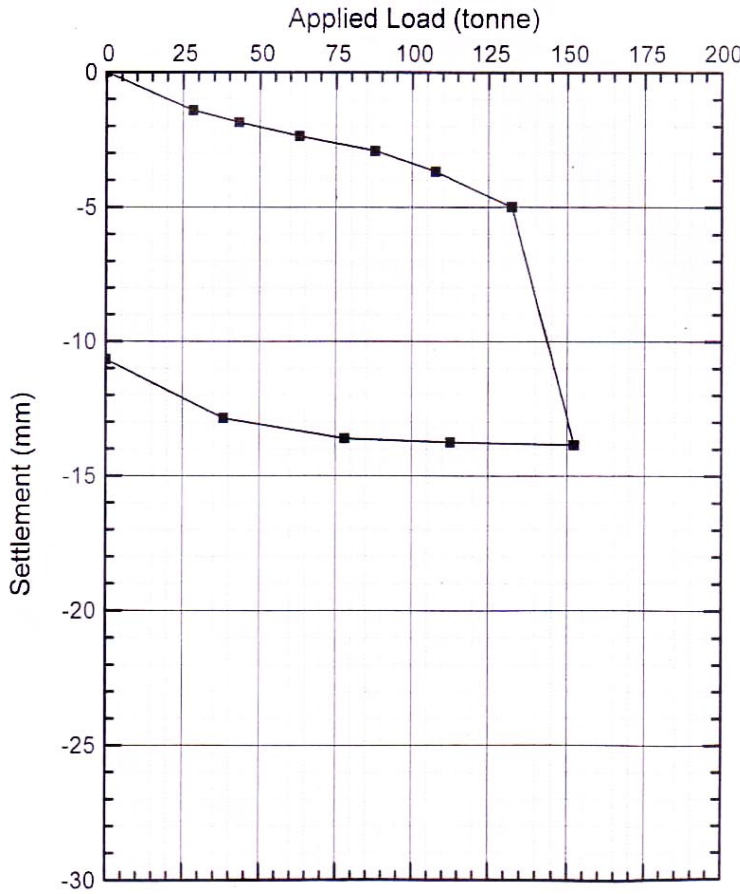

Fig. 14 Load-settlement curve of the tested pile group [7].

\section{References}

[1] B.H. Fellenius, The analysis of results from routine pile load tests, Ground Engineering 13 (6) (1980) 19-31.

[2] F.M. Fuller, H.E. Hoy, Pile load tests including quick-load test method, conventional methods and interpretations, Highway Research Records 333 (1970) 74-86.

[3] G. Weiming, D. Guoliang, J. Yongsheng, X. Guoya, Theory and practice of self-balanced loading test for pile bearing capacity, Journal of Building Structures 1 (2002) 82-88.

[4] M.F. Randolph, Science and empiricism in pile foundation design, Géotechnique 53 (10) (2003) 847-875.

[5] M. Lee, J.H. Lee, Prediction of pile bearing capacity using artificial neural networks, Elsevier 18 (3) (1996) 189-200.

[6] R.D. Rieke, J.C. Crowser, Interpretation of pile load test considering residual stresses, Journal of Geotechnical Engineering 113 (4) (1987) 320-334.

[7] Report on Results of Pile Load Test on Cast-in-Situ Service Group Pile for the Strengthening of Existing Cleaner Colony Buildings at Dhalpur (Building-A) of Dhaka City Corporation, Department of Civil Engineering, Bureau of Research, Testing and Consultants (BRTC), Bangladesh University of Engineering and Technology (BUET), 00574/09-10/CE, 2010.

[8] Work Details Archive, Dhaka City Corporation, Dhaka, Bangladesh, 2010. 